\title{
UNDERSTANDING MULTIMODAL ACCESSIBILITY PARAMETERS IN DIVERSE URBAN ENVIRONMENTS: A PILOT STUDY IN DARMSTADT
}

\author{
LAKSHYA PANDIT \& MARTIN KNÖLL \\ Urban Health Games, FB15, TU Darmstadt, Germany
}

\begin{abstract}
The research takes into consideration diverse perspectives and parameters for assessing accessibility in urban spaces within the Frankfurt Rhein-Main Area, with the initiation of pilot study in Darmstadt, being one of the major cities forming the urban agglomeration. Diverse tools including public transport accessibility level and Space Syntax which contribute to the factor of accessibility are studied and utilized in different urban spaces and further correlated. The study takes into consideration the city centre, the main transit station and a residential area, as three urban spaces within Darmstadt, to understand how the selected performance measures quantify leading to qualitative learning and inferences. The study aims to further evolve in future stages, in order to understand the diversity through the accessibility performance measures through different cities, based on commuter flows, within the urban agglomeration. Assessing accessible mobility in continuum within the urban agglomeration, through interdisciplinary means of research methodology, would assist in the vision (as per German legislation) of obtaining an accessible and integrated multimodal transport system by 2022 .

Keywords: accessibility, agglomeration, mobility.
\end{abstract}

\section{INTRODUCTION}

In an urban environment, majority of trips include a sequence of travel modes in order to reach a destination. A multimodal transportation system allows people to use a variety of transportation modes, including walking, biking and other mobility devices, as well as transit where possible. These modal integrations may differ in their functional capacities, in continuum, in different urban environment. Such a system reduces dependence on automobiles and encourages more active forms of personal transportation, improving health outcomes and increasing the mobility of those who are unable or unwilling to drive [1].

The research tends to identify the state of the art benchmarking accessibility tools, in order to study the multimodal accessibility within urban agglomerations. The study is prioritized on the urban agglomerations with strategic vision towards obtaining an objective of enhanced mobility in future. With respect to the strategic vision of Mobiles Hessen 2035, the short-distance mobility must again be the basis of mobility for cities and towns [2], with Frankfurt Rhein-Main region being one of the major urban agglomerations within the state of Hessen. According to regional planning definition, Frankfurt Rhein-Main Metropolitan region includes seven independent cities of Frankfurt am Main, Offenbach am Main, Wiesbaden, Mainz, Worms, Darmstadt and Aschaffenburg, along with 18 counties. The cities lend the region its metropolitan character, a polycentral city system held together with a strong network. As per the 2018 data, the commuter flow within the Frankfurt Rhein-Main region shows the major cities, including Wiesbaden, Offenbach, Mainz and Darmstadt, which contribute towards the major mobility share in the region. Majority of these commuter flows are directed towards the city of Frankfurt within the Hessen state. The cities dominant with the commuter flows in the urban agglomeration fell within the urban districts 
of the state of Hessen, excluding Mainz, which lies within the Rhineland-Palatinate state in the urban district [3]. With the onset of population growth and increase in mobility demands, access and priority of diverse means of mobility, especially short-distance mobility, have to be taken into consideration.

\section{UNDERSTANDING ACCESSIBILITY AND ITS PARAMETERS}

With the onset of ongoing urban studies, defining accessibility within the urban context takes various perspectives. With respect to Engwicht, accessibility refers to the ease of arrival to facilities, activities or goals, which could be appointed in general as opportunities. Accessibility could be defined as the intensity of possibility of interaction and exchange [4]. Litman interprets the definition with respect to the profession of the individuals, to which the boundaries and scope limit itself to. With respect to the land-use planner, geographical accessibility, i.e. distances between activities, is the major focus, whereas for transport planners, more focus is generated upon the mobility aspect [5].

There has been a paradigm shift from conventional mobility planning, which placed automobiles at the nucleus of the transportation system to a more accessible-based planning which places people at the centre of the planning process. Bertolini defines accessibility through a medium of space as a node, with an accessible public space being one where many different people can come and also do many different things [6]. The public space is treated as a central accessible nodal point and also includes the spaces within the node. This approach focuses more upon the diverse human mobility factors with a barrier-free environment, serving as an inclusive space with higher degree of accessibility. The statement also defines that the focal point acts as a node; in other words there are other nodes which act as spaces, which are not necessarily public spaces but other elements like pedestrian junctions, public transportation service stops, etc.

Assessing accessibility is often difficult to interpret, and understanding the performance measures which take into account the qualities contributing towards the overall perspective of accessibility is taken into consideration through literature studies (Fig. 1). The measures reviewed were based on the similar boundaries with respect to the micro- and macro-scales, which help in relating the different perspectives of assessing accessibility and understanding the inter-parametrical relations through the urban scenario. The research focuses on understanding how these perspectives can be utilized in order to understand and improve the accessibility paradigm through multimodal mobility.

\subsection{Selection of accessibility parameters}

The research takes into consideration three parameters for the pilot study, through a transition, from a micro- to macro-based perspective, involving modes of travel limiting to public transport i.e. bus, tram, train and pedestrian access. The measures include public transport accessibility level (PTAL), intelligibility and connectivity index. The area of observation for the assessment of the last two parameters is limited within $1 \mathrm{~km}^{2}$. With respect to the PTAL, the 640-m radius limits the study for the bus service stations and 960-m radius limits the study for the rail service stations. These boundaries are based on the comfortable walking timeframe for human limiting to $8 \mathrm{~min}$ and $12 \mathrm{~min}$ for the services, respectively [7] (Fig. 2). The selected parameters and their perspective with respect to accessibility are discussed in the following sections. 


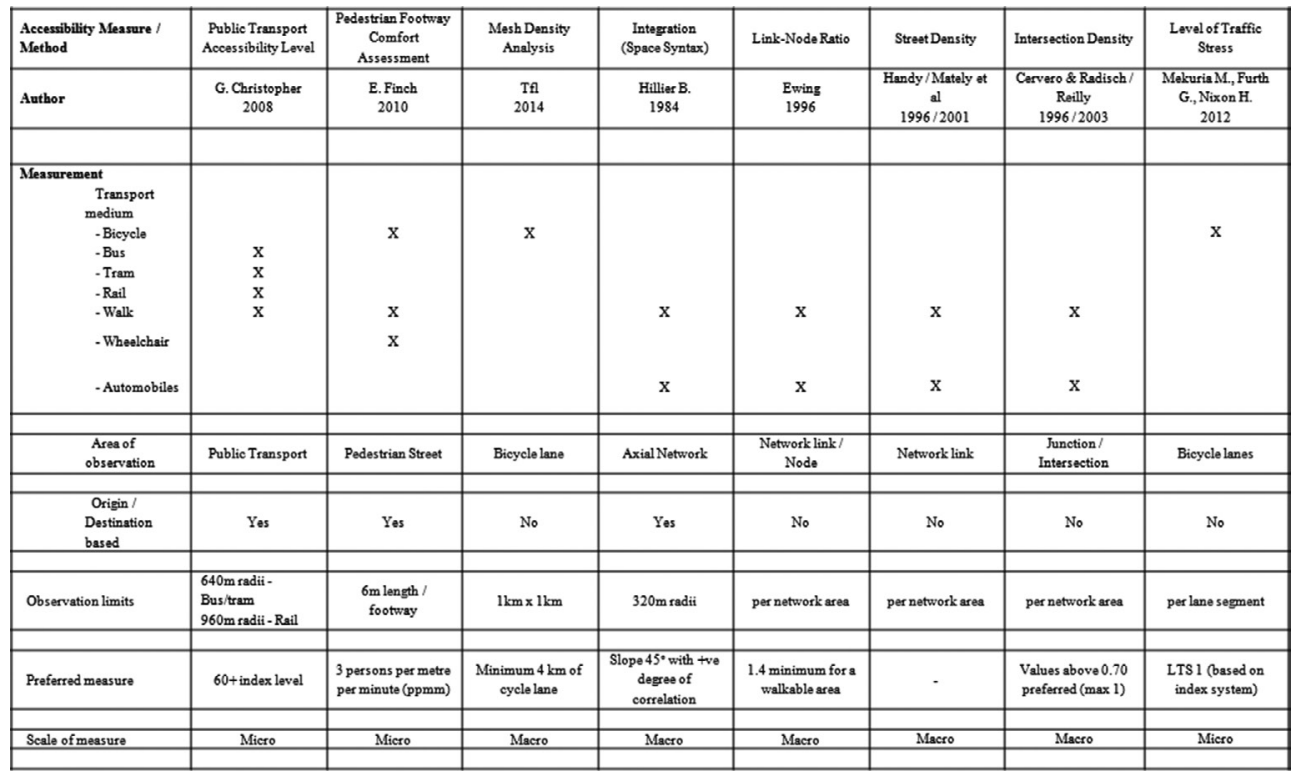

Figure 1: State-of-the art measures focusing on accessibility-based paradigm.

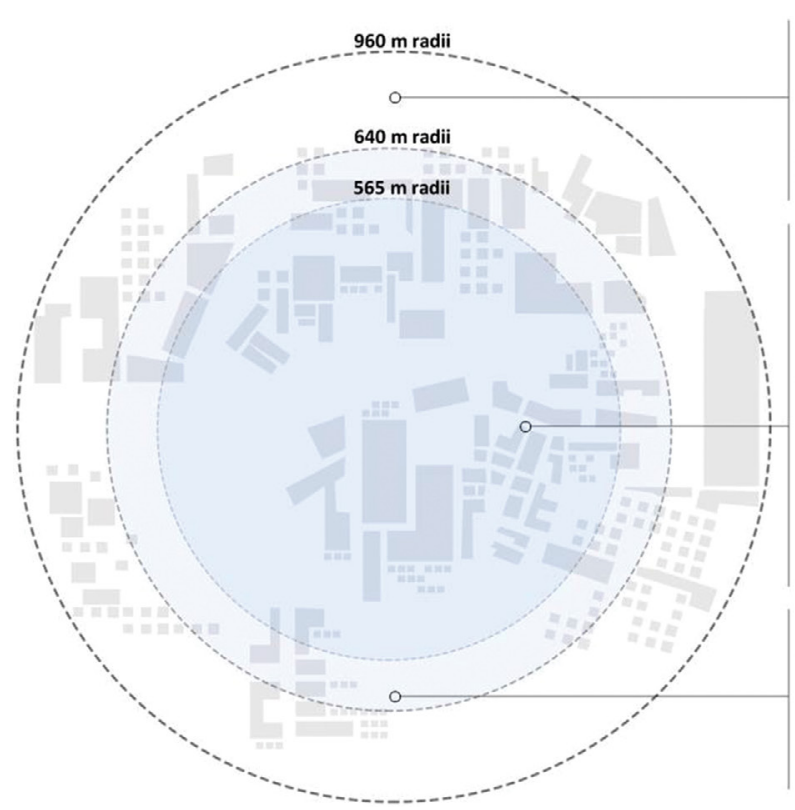

\author{
PTAL (Rail services: $960 \mathrm{~m}$ \\ Quantitative measure: \\ Takes into consideration the shortest walkable pedestrian pathway \\ (metric distance) to the respective rail service stations. \\ Accessibility perspective: \\ Access to rail service station with respect to how close the rail service \\ stotion is with respect to the central node of the selected urban \\ space, with an added factor of service frequency. \\ Connectivity Index (1 sq. km) \\ Quantitative measure: \\ Takes a road network with links and nodes into consideration \\ for the calculation of the ratio. \\ Accessibility perspective: \\ Access to a 'walkable' network with respect to the corresponding \\ ratio. Indirectly showcases the degree of freedom of movement \\ w.r.t. pedestrians. \\ Intelligibility (1 sq.km) \\ Quantitative measure: \\ Takes a network of visible lines of sight (axial lines) within an urban \\ scale into consideration. \\ Accessiblity perspective: \\ Access to a navigable network of interconnected spaces in an urban \\ scale. \\ PTAL (Bus services: $640 \mathrm{~m}$ ) \\ Quantitative measure: \\ Takes into consideration the shortest walkable pedestrian pathway \\ (metric distance) to the respective bus / tram service stations. \\ Accessibility perspective: \\ Access to rail service station with respect to how close the \\ bus station is with respect to the central node of the \\ selected urban space, with an added factor of service frequency.
}

Figure 2: Accessibility perspectives and observation boundaries within selected parameters. 


\subsubsection{Public Transport Accessibility Level (PTAL)}

The methodological index was developed in 1992 by the London Borough of Hammersmith and Fulham. The index takes into consideration the walk access times and the service availability of the transportation modes during the morning peak hours within a predefined zone from a point of interest (poi).

Walk times are calculated from specified points of interest to all public transport service access points, i.e. bus stops, rail stations, underground stations and tram stations. For the calculation of the walk access time, assumed average human walking speed of $4.8 \mathrm{kph}$ is taken into consideration with respect to the shortest accessible pathway. The walk access time $\left(T_{\text {wat }}\right)$ along with the average waiting time $\left(T_{\text {awt }}\right)$ for the service leads to the total access time $\left(T_{\text {tat }}\right)$. The total access time is later converted into equivalent doorstep frequency (EDF), which determines a measure as if the transport service was available at the doorstep. With respect to the maximum frequency of the service, the weightage of 1 is given to the particular route, as compared to the others with 0.5 weightage. The overall process is summed up as follows:

$$
\begin{aligned}
& T_{\text {tat }}=T_{\text {wat }}+T_{\text {awt }} \\
& T_{\text {awt }}=[0.5 \times(60 / f)]+r \\
& \mathrm{EDF}=30 / T_{\text {tat }}
\end{aligned}
$$

The time measure is calculated in minutes for the index, with $f$ denoting the morning peak hour service frequency and $r$ being the reliability factor with respect to late services. The reliability factor for bus services is $2 \mathrm{~min}$ while that for rail services is $0.75 \mathrm{~min}$ [8].

$$
\begin{aligned}
& I_{\text {mode }}=\mathrm{EDF}_{\text {max }}+\mathrm{EDF}_{\text {others }} \times 0.5 \\
& I_{\text {poi }}=\Sigma I_{\text {modes }}
\end{aligned}
$$

Overall, the cumulative indexes for each mode is calculated in order to achieve an overall index $\left(I_{\text {poi }}\right)$ value. The indexes are categorized into six levels, with 1 (1a and $\left.1 \mathrm{~b}\right)$ being the lowest level of accessibility, with the index value below 5.01 (for $1 \mathrm{~b}$ ), and 6 ( $6 \mathrm{a}$ and $6 \mathrm{~b}$ ) being the highest level of accessibility, with the index value above 40.00 (for $6 \mathrm{~b}$ ).

\subsubsection{Intelligibility}

Space Syntax is becoming a flourishing paradigm for spatial studies, increasingly well integrated with other approaches and increasingly expanding its scope and scale of investigation. The real test of theory and method is its application in the real world of projects and development. The intelligibility parameter is based on the Space Syntax theory of spaces, where spaces are treated as voids. These voids may differ in diverse scales based on the degree of measurement, i.e. ranging from streets or a public plaza to a room inside a building. Regarding intelligibility, the parameter takes into consideration integration that involves the utility of axial lines through the urban scales of street network [8].

Hillier explains the integration (or global integration) property by analysing how deep or shallow each line is from one another in the system. Analysing how deep or shallow each line 

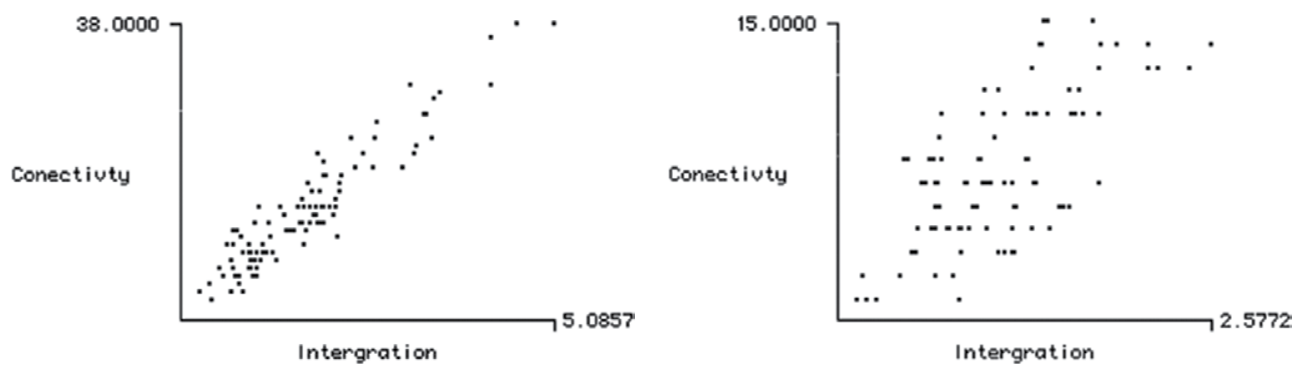

Figure 3: Spatial layout with strong intelligibility (left) and weak intelligibility (right) (Source : Hillier B., 1996 [8]).

is from other lines up to three steps away is termed as radius-3 integration (or local integration), which has a close relation to determine pedestrian movements [9] and also acts as a good predictor of a place being relaxing to pedestrians in open public spaces as opposed to global integration [10]. Limiting the radius to 1 is termed as connectivity (within the Space Syntax theory), which in simple terms determines how many immediate axial lines a particular line is connected with. Intelligibility is a property, which is based on the correlation of connectivity and global integration. A strong positive correlation determines a space to be intelligible, which is a quality of network of spaces to be easily navigable. A scatter plot of an intelligible and unintelligible space (Fig. 3) shows how the points around the regression line exhibit less deviation for an intelligible space, whereas they segregate and show weak correlation for an unintelligible space.

\subsubsection{Connectivity Index}

It is computed by dividing the number of roadway links by the number of roadway nodes in a predefined network. Links are the segments between intersections, and the node are the intersections themselves. Cul-de-sac heads count the same as any other link end point. The result can be calculated separately for pedestrian and cycling access, taking into account connections and links for non-motorized travel, such as a path that connects the ends of two culde-sacs. Ewing suggests the link-node ratio of 1.4, that is about halfway between the extreme values, to be a good ratio for a network planning process [11]. Close proximity towards the suggested link-node ratio denotes a bare minimum for a walkable network.

The ratio decreases to a great extent with the introduction of cul-de-sacs within the existing network (Fig. 4). The index reduces by 0.08 on the introduction of three cul-de-sacs on the existing nodal points and reduces further by 0.13 on the introduction on the existing links within the system. The measure of cul-de-sacs reduces the overall degree of freedom for the users within the mobility system, and further studies on the networks would acknowledge how the diverse environments behave with respect to other parameters.

\section{SELECTION AND ASSESSMENT OF SPACES FOR THE PILOT STUDY}

The pilot study is an experimental preliminary study, in order to evaluate the time and performance of the selected accessibility parameters, in turn also identifying problems pertaining to the process, prior to main assessment of the identified parameters within the cities forming Frankfurt Rhein-Main Region within Hessen. The study helps in preliminary understanding 

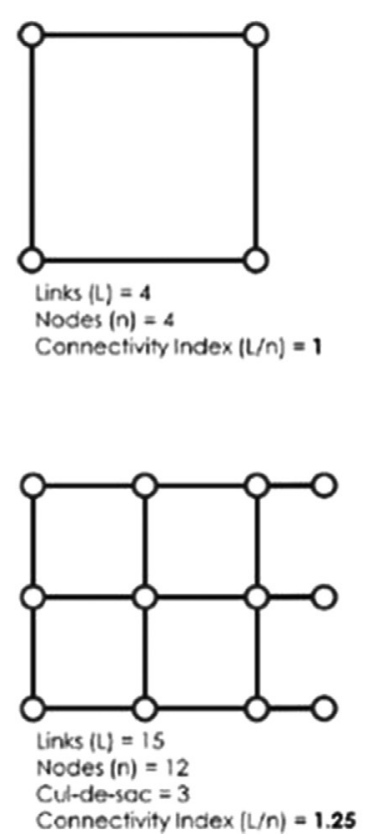
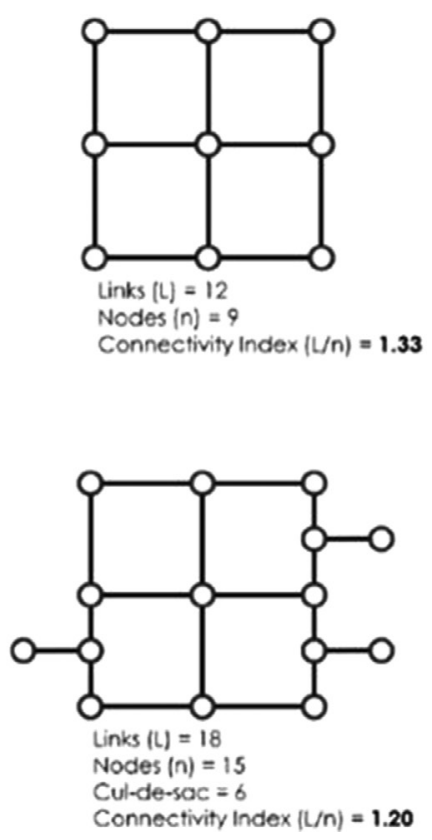
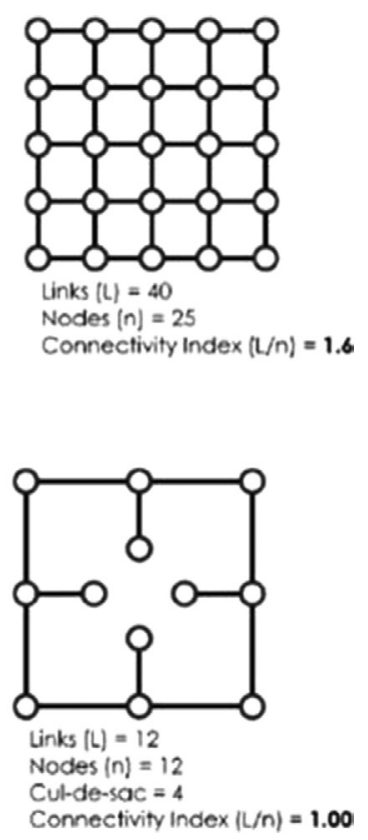

Figure 4: Link-node ratios of the network with and without cul-de-sacs.

of the urban fabric, which assists and brings more clarity in research stages within the selected parameters to be studied upon. The study assists in modifying the digitized spaces, which are usually skipped during the desk-based approach. Post reconnaissance visit, the parameters are examined with ease due to better knowledge of the immediate surroundings within the core of the selected urban spaces.

With respect to the research timeline, the pilot study initiates within the city of Darmstadt. The urban spaces identified for the assessment include the city centre, i.e. Luisenplatz, which represents the commercial high street environment within the city; the main railway station, i.e Darmstadt Hauptbahnhof, which represents an important transit hub for the inter-city mobility within the urban agglomeration; and Komponistenviertel, which represents the residential environment within the north east section of the city, including the central junction within the commuter lane connecting the local street network (Fig. 5). The diversity of the
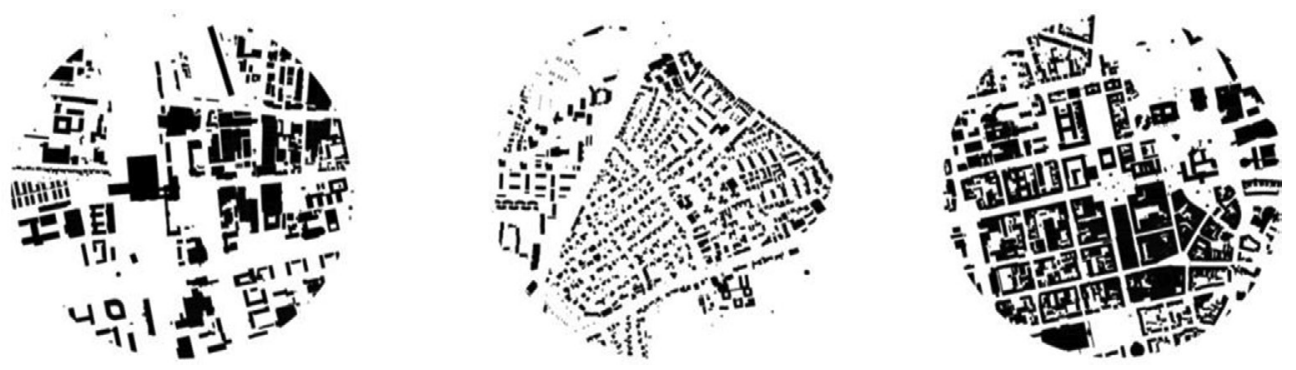

Figure 5: Figure ground maps of Hauptbahnhof (left), Komponistenviertel (centre) and Luisenplatz (right) within a $565 \mathrm{~m}$ radius $(\sim 1$ sq.km.). 
selected areas resonate to the functionalities and land-use typology, where the studies are aimed to be carried out to study various performance measures and have a learning outcome through a comparative study.

In future assessment of the spaces, Space Syntax would be further utilized, through its property of integration, in order to prioritize the Pedestrian Footway Comfort in local integrated streets, which suggest higher pedestrian flow. These streets would be assessed for peak pedestrian flows and a comfort index would be generated.

\subsection{Parametric assessment}

With respect to the selected urban spaces, three measures identified for the assessment were studied, especially PTAL during the morning hours on weekdays when there were no unusual activities or holidays, leading to atypical frequency of the modal services. With respect to the digitization, different maps were digitized with respect to different measures, i.e. with respect to the connectivity index measure, the centre lines of the streets were taken into consideration for mapping the selected network, whereas with respect to the intelligibility measure, axial lines were drafted within the depthmapX software [12], which were the lines of longest sight within the selected voids of the street network.

\subsubsection{PTAL assessment for the pilot study}

The major factors contributing towards the calculation for the PTAL include the frequency of the modes on the service station with respect to their route and the shortest accessible pathway for the pedestrians from the poi to all the service stations taken into consideration. Darmstadt Hauptbahnhof (D. Hbf.) is served with three modes taken into consideration, as compared to two modes each for Luisenplatz and Komponistenviertel. Several modal frequencies were recorded around Hauptbahnhof, with the farthest service station at approximately $480 \mathrm{~m}$ from the poi (Fig. 6).

Diverse routes of buses, trams and trains were recorded with maximum frequency of 6 within the observed time interval (Table 1). The modal routes were only considered once during the assessment for a single selected area, with priority to the service station closest to the poi, as compared to the other service station with similar modal routes.

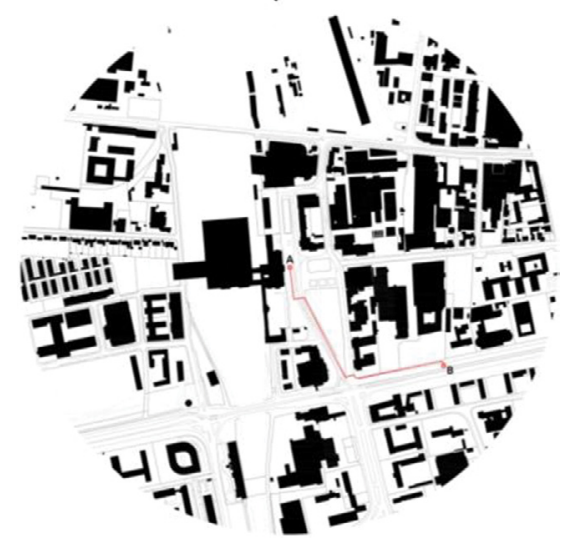

Figure 6: Shortest pedestrian access between the point of interest A at Hauptbahnhof and B at Berliner Allee (B. Allee) service station. 
Table 1: The PTAL index for respective modal service stations within Hauptbahnhof area.

\begin{tabular}{|c|c|c|c|c|c|c|c|c|c|c|c|}
\hline Site & Service & Stop & Route & Distance & $f$ & Weight & $T_{\text {wat }}$ & $T_{\text {awt }}$ & $T_{\text {tat }}$ & EDF & Index \\
\hline \multirow[t]{25}{*}{ D. Hbf. } & \multirow[t]{13}{*}{ Bus } & \multirow[t]{13}{*}{ D. Hbf. } & $\mathrm{H}$ & 103 & 6 & 1 & 1.29 & 7.00 & 8.29 & 3.62 & 3.62 \\
\hline & & & 40 & 103 & 1 & 0.5 & 1.29 & 32.00 & 33.29 & 0.90 & 0.45 \\
\hline & & & 5,513 & 103 & 2 & 0.5 & 1.29 & 17.00 & 18.29 & 1.64 & 0.82 \\
\hline & & & 671 & 103 & 2 & 0.5 & 1.29 & 17.00 & 18.29 & 1.64 & 0.82 \\
\hline & & & 672 & 103 & 1 & 0.5 & 1.29 & 32.00 & 33.29 & 0.90 & 0.45 \\
\hline & & & 675 & 103 & 1 & 0.5 & 1.29 & 32.00 & 33.29 & 0.90 & 0.45 \\
\hline & & & AIR & 103 & 2 & 0.5 & 1.29 & 17.00 & 18.29 & 1.64 & 0.82 \\
\hline & & & $\mathrm{F} / \mathrm{U}$ & 103 & 5 & 0.5 & 1.29 & 8.00 & 9.29 & 3.23 & 1.62 \\
\hline & & & $\mathrm{K}$ & 103 & 6 & 0.5 & 1.29 & 7.00 & 8.29 & 3.62 & 1.81 \\
\hline & & & MO1 & 103 & 1 & 0.5 & 1.29 & 32.00 & 33.29 & 0.90 & 0.45 \\
\hline & & & $\mathrm{NH}$ & 103 & 1 & 0.5 & 1.29 & 32.00 & 33.29 & 0.90 & 0.45 \\
\hline & & & $\mathrm{R}$ & 103 & 3 & 0.5 & 1.29 & 12.00 & 13.29 & 2.26 & 1.13 \\
\hline & & & RH & 103 & 3 & 0.5 & 1.29 & 12.00 & 13.29 & 2.26 & 1.13 \\
\hline & \multirow[t]{6}{*}{ Tram } & \multirow[t]{5}{*}{ D. Hbf. } & 1 & 32 & 3 & 0.5 & 0.40 & 10.75 & 11.15 & 2.69 & 1.35 \\
\hline & & & 2 & 32 & 4 & 0.5 & 0.40 & 8.25 & 8.65 & 3.47 & 1.73 \\
\hline & & & 3 & 32 & 6 & 1 & 0.40 & 5.75 & 6.15 & 4.88 & 4.88 \\
\hline & & & 5 & 32 & 4 & 0.5 & 0.40 & 8.25 & 8.65 & 3.47 & 1.73 \\
\hline & & & 9 & 32 & 4 & 0.5 & 0.40 & 8.25 & 8.65 & 3.47 & 1.73 \\
\hline & & B. Allee & 4 & 478 & 4 & 0.5 & 5.98 & 8.25 & 14.23 & 2.11 & 1.05 \\
\hline & \multirow[t]{6}{*}{ Train } & \multirow[t]{6}{*}{ D. Hbf. } & S3 & 150 & 2 & 1 & 1.88 & 15.75 & 17.63 & 1.70 & 1.70 \\
\hline & & & RB66 & 150 & 1 & 0.5 & 1.88 & 30.75 & 32.63 & 0.92 & 0.46 \\
\hline & & & RB68 & 150 & 1 & 0.5 & 1.88 & 30.75 & 32.63 & 0.92 & 0.46 \\
\hline & & & RB75 & 150 & 2 & 0.5 & 1.88 & 15.75 & 17.63 & 1.70 & 0.85 \\
\hline & & & RB81 & 150 & 1 & 0.5 & 1.88 & 30.75 & 32.63 & 0.92 & 0.46 \\
\hline & & & RE60 & 150 & 1 & 0.5 & 1.88 & 30.75 & 32.63 & 0.92 & 0.46 \\
\hline
\end{tabular}

The overall PTAL value of 30.89 fell within the index range of 25.01-40.00, depicting an excellent index value under group 6a. The major contribution to the overall PTAL value is given by 14.02 by bus, followed by 12.47 under the mode of tram and 4.39 index value through train. The proximity and high frequency of trams, buses and train services assist in the overall PTAL value for Darmstadt Hauptbahnhof. With respect to the residential area of Komponistenviertel, the service stations within the radius of examination were recorded to be only 2, With both being on the north and south ends of the selected residential area, identified as Regerweg and Alfred Messel Weg, respectively. The modal service of bus is attained within the area with maximum frequency of 4 , during the peak hour, at the southern end of Regerweg. This assists in overall PTAL index of 3.09, which falls within the index range of 2.51-5.00, denoting a poor value under group 1b. Overall, the service stations received two service routes, which was the least as compared to the other selected areas for the study. Luisenplatz is served with the maximum service stations, with respect to bus and tram services, accounting to 29 service routes. The area has a close proximity to the available service stations around the major landmark of the central bust in the pedestrian plaza, making the services accessible on a level ground. 


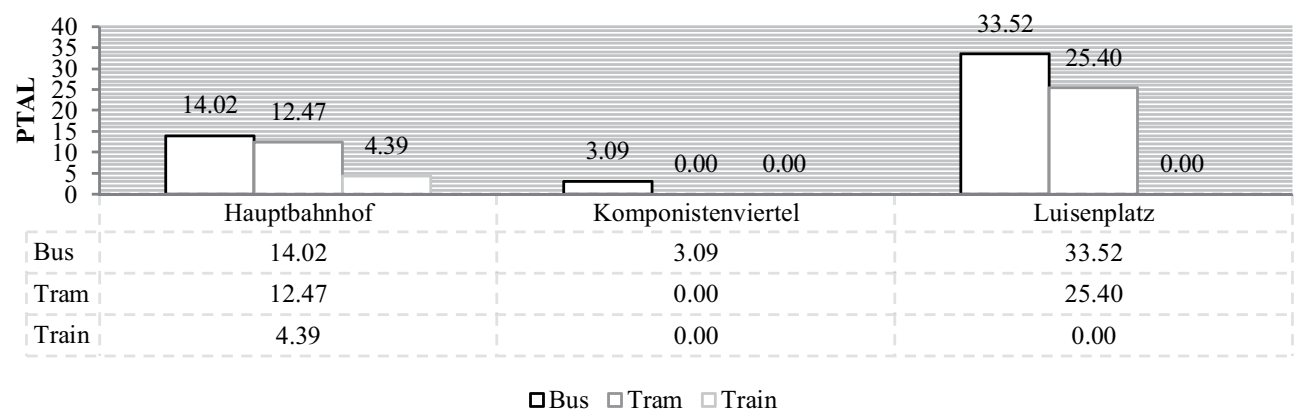

Figure 7: PTAL for selected urban spaces in Darmstadt for the pilot assessment.

As compared to the other two selected areas, Luisenplatz served with the highest PTAL index value of 58.90, which fell in the highest attainable range of $40.01+$ within the $6 \mathrm{~b}$ category. The major share of the PTAL index is contributed by bus modal services through overall index value of 33.52, followed by tram services through the overall index value of approximately 25.40 (Fig. 7). The modal services contributed to the highest modal PTAL index in Luisenplatz among the three selected areas, with modal bus service meeting the highest share in each observation area.

\subsubsection{Intelligibility assessment for the pilot study}

Regarding intelligibility, the axial maps were drafted with respect to the selected urban areas and were linked and de-linked in the depthmapX software utilizing the Space Syntax theory (Fig. 8). The axial lines around the Darmstadt Hauptbahnhof show high values in global integrations $(\mathrm{r}=\mathrm{n})$ on the Bismarckstrasse and Rheinstrasse, in the north and south ends of the Hauptbahnhof, respectively, with a coefficient of correlation between the connectivity and global integration of 0.53 . This shows a good positive correlation between the identified parameters, i.e. a good intelligibility in these streets, which are approximately $200 \mathrm{~m}$ away and with no immediate visible connection to the main station entrance. The global axial integration of the axial network in the residential area of the Komponistenviertel shows major integrations in the core area around the Flowtowstrasse, with a coefficient of correlation between the connectivity and global integration of 0.57 . The axial line with major
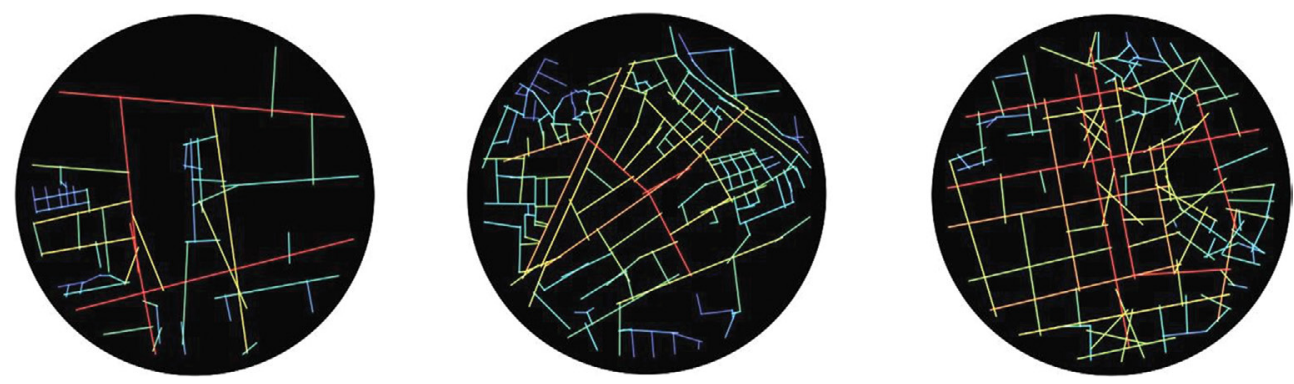

Figure 8: Axial maps (global integration) of Darmstadt Hauptbahnhof (left), Komponistenviertel (centre) and Luisenplatz (right) within $1 \mathrm{~km}^{2}$ area. 


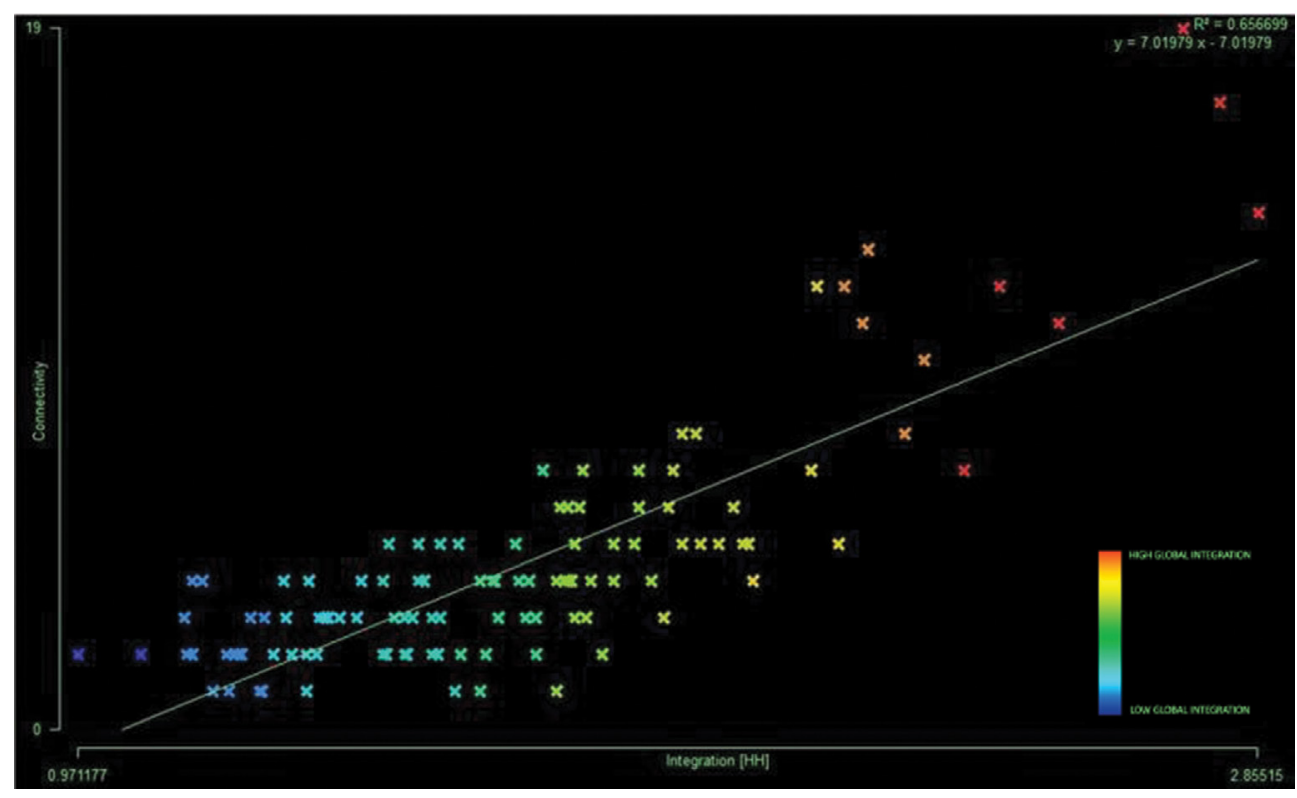

Figure 9: Scatter plot of global integration $(r=n)$ vs connectivity $(r=1)$ of Luisenplatz, Darmstadt $\left(\sim 1 \mathrm{~km}^{2}\right)$.

connectivity lies in the north on the Alfred Messel Weg, in contrast to the major integrated axial line around Flowtowstrasse.

The axial maps of the selected urban spaces show a positive correlation between the connectivity and the global integration, i.e. intelligibility, with the highest coefficient of correlation value 0.81 in the city centre of Darmstadt, i.e. Luisenplatz (Fig. 9). This shows a high intelligibility characteristic of the area as compared to the main transit station and the residential area, i.e. Komponistenviertel, indicating that the axial network of the city centre has more ease of navigation as compared to the axial network of the other two areas.

Within the three selected areas, the axial network with better connectivity value and within the high integration value range, showed better intelligibility, which was the case in Luisenplatz. In Hauptbahnhof and the residential area, the links with highest connectivity were not within the range of high integration value, whereas in the city centre, the link with high connectivity correlated to high integration value. The legibility of spaces [13] with respect to distinct characteristics, signage and street furniture could be utilized as a way of improving intelligibility through least changes in urban form. With further observations in other selected areas within the urban agglomerations, more clarity in the relation to the intelligibility factor would be understood.

\subsubsection{Connectivity index assessment for the pilot study}

With respect to the connectivity index, the selected urban areas were in close proximity to the link-node ratio of 1.4, which denotes a bare minimum for a walkable network [11]. The Darmstadt Hauptbahnhof area had nodal density of 84 per unit square kilometre and a link density of 123 per unit square kilometre. The major cul-de-sacs were located in the east from the main station within the network area. With respect to the residential area of the 

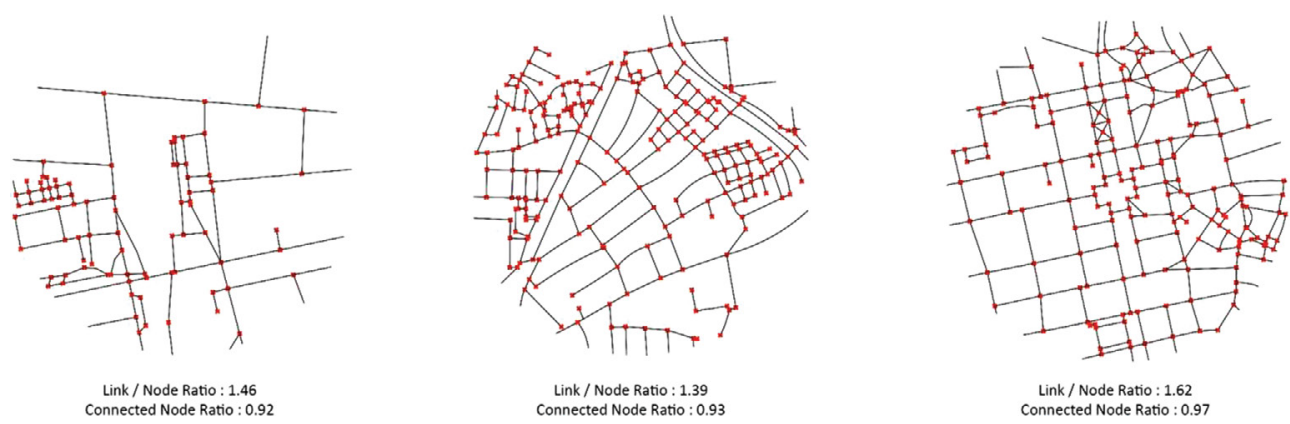

Figure 10: Node density mapping of Darmstadt Hauptbahnhof (left), Komponistenviertel (centre) and Luisenplatz (right) within $1 \mathrm{~km}^{2}$ area.

Komponistenviertel, the nodal density of 232 per unit square kilometre was observed with a link density of 324 per unit square kilometre. The area had the cul-de-sac density of 16, with major concentration around the north-west and in the east direction from the Alfred Messel Weg. Luisenplatz had a network density of 188 nodes and 305 links per unit square kilometre. The cul-de-sac density was much lower, as compared to the Komponistenviertel, with major concentrations around the west and eastern ends from the Mathildenplatz. Luisenplatz had the maximum link-node ratio of 1.62, as compared to 1.46 in Hauptbahnhof and 1.39 in Komponistenviertel (Fig. 10). The network of nodes and links around the high street zone of Luisenplatz supports a more walkable network as compared to the other zones of selected residential and main railway station area in Darmstadt. As compared to the other selected parameters, the connectivity indexes for the selected urban spaces are closer to the desired value corresponding towards a good walkable network of links and nodes.

\subsubsection{Comparison of performance measures}

In order to have an overall perspective of parameters based on the typology of land use, the selected urban spaces are ranked through a comparative study. Post the completion of the pilot studies through an epistemological timeline with three performance measures, the multi-criteria decision analytic tool, i.e. TOPSIS (Technique for Order of Preference by Similarity to Ideal Solution), which bases the best measure to have the shortest distance (i.e. the Euclidean distance) from the ideal solution, is utilized.

For the correlation, the equal distribution of weightage is given to the respective three parameters for the pilot study (Table 2), which may be altered with respect to the varied priorities of the user groups in the respective areas. One of the possible tools for obtaining improved weightage on prioritization would be based on analytic hierarchy process, post survey outcomes in future. The correlation with respect to the measures show that the city centre, i.e. Luisenplatz, offers an improved degree of freedom in a walkable environment as compared to the other spaces, which assists the navigable environment for the users and better access to public transport.

This supports the gained hypothesis, which according to Murphy [14], bases central business districts to be more accessible and concentrated with public transport and pedestrian traffic. Due to better network of connected spaces, the navigation around the city centre played a major role as compared to the residential and major transit station. This assists in prioritization of the urban spaces with respect to the accessibility parameters and vice versa. 
Table 2: (a) Normalized decision matrix of selected measures and (b) performance ranking (PR) of the selected spaces based on Euclidean distance under TOPSIS measure.

\begin{tabular}{lllc}
\hline Performance measures & Connectivity index (c) & Intelligibility (i) & PTAL (p) \\
\hline Hauptbahnhof & 1.46 & 0.53 & 30.88 \\
Komponistenviertel & 1.39 & 0.57 & 3.09 \\
Luisenplatz & 1.62 & 0.81 & 58.92 \\
$\left.\sqrt{[}(x 1)^{2}+\ldots(x n)^{2}\right]$ & 2.58 & 1.12 & 66.59 \\
\hline
\end{tabular}

Normalized decision matrix

\begin{tabular}{llll} 
Performance measures & Connectivity index (c) & Intelligibility (i) & PTAL (p) \\
\hline Hauptbahnhof & 0.56 & 0.47 & 0.46 \\
Komponistenviertel & 0.54 & 0.51 & 0.05 \\
Luisenplatz & 0.63 & 0.72 & 0.88 \\
\hline
\end{tabular}

(a)

\begin{tabular}{|c|c|c|c|c|c|c|c|c|}
\hline $\begin{array}{l}\text { Weighted } \\
\text { normalized } \\
\text { decision } \\
\text { matrix } \\
\text { (weighted } \\
\text { at } 0.33 \text { ) }\end{array}$ & & & & & & & & \\
\hline $\begin{array}{l}\text { Perfor- } \\
\text { mance } \\
\text { measures }\end{array}$ & $\begin{array}{l}\text { Connec- } \\
\text { tivity } \\
\text { index (c) }\end{array}$ & $\begin{array}{l}\text { Intelligi } \\
\text { bility (i) }\end{array}$ & $\begin{array}{l}\text { PTAL } \\
\text { (p) }\end{array}$ & $\begin{array}{l}\text { E.distance } \\
\text { from ideal } \\
\text { best }(e b= \\
\sqrt{ }\left[(c-b)^{2}+\right. \\
\left.(i-b)^{2}+(p-b)^{2}\right]\end{array}$ & $\begin{array}{l}\text { E.distance } \\
\text { from ideal } \\
\text { least }(e l= \\
\sqrt{ }\left[(c-1)^{2}+(i-1)^{2}\right. \\
\left.\left.+(p-1)^{2}\right]\right)\end{array}$ & $\begin{array}{l}e b+e l \\
2\end{array}$ & $\begin{array}{l}l \text { Perfor- } \\
\text { mance } \\
\text { score } \\
(e l / e l+e b)\end{array}$ & PR \\
\hline $\begin{array}{l}\text { Hauptbah- } \\
\text { nhof }\end{array}$ & 0.185 & 0.155 & 0.151 & 0.164 & 0.135 & 0.299 & 0.452 & 2 \\
\hline $\begin{array}{l}\text { Kompon- } \\
\text { istenviertel }\end{array}$ & 0.178 & 0.168 & 0.016 & 0.284 & 0.013 & 0.297 & 0.044 & 3 \\
\hline Luisenplatz & 0.208 & 0.238 & 0.290 & 0.000 & 0.288 & 0.288 & 1.000 & 1 \\
\hline $\begin{array}{l}\text { Ideal (best) } \\
\text { value i.e b }\end{array}$ & 0.208 & 0.238 & 0.290 & & & & & \\
\hline $\begin{array}{l}\text { Ideal (least) } \\
\text { value i.e l }\end{array}$ & 0.178 & 0.155 & 0.016 & & & & & \\
\hline
\end{tabular}

(b)

With respect to the pedestrian traffic, further assessments are to be carried in the respective spaces to gain more aspects and learning towards an accessible multimodal system. The data collection and correlation is an amalgamation of on-desk and on-site process, including certain timeframes to be followed for different parameters, which should be taken into account with respect to the future research timeline. 


\section{CONCLUSIONS}

Through on-site data collection and analysis, the diverse urban fabric showed its respective characteristic through the selected parameters. Within the residential area, the collector lanes reflected the low PTAL value, which was reflected on-site through the occupancy of more cars on the streets and less pedestrian pathways. The lack of access to service stations in the residential area, as compared to the other selected spaces of city centre i.e. Luisenplatz, and main railway station i.e. Hauptbahnhof, addresses the need to obtain more access towards the modes of public transport. The shortest walking distance towards the nearest service station, within the residential area, was the longest as compared to the service stations in the other selected urban spaces. The axial streets with high connectivity values, within Space Syntax theory, showed great correlation with respect to the global integration value in the city centre, which in turn had a high link-node ratio demonstrating a better walkable network of spaces. The overall high local integration values give a better perspective of short-distance mobility, as they predict high pedestrian movements, as compared to the global integration values. The navigable environment with respect to the pedestrians require an added perspective of bicycle users, as the movement of cyclists are angular in nature and require a perspective of least route deviations. Currently, the pilot assessment shows how the selected spaces within a travel chain perform on selected aspects of accessibility through connectivity of network, intelligibility of voids in the urban scale and closeness to public transport.

In order to have an enhanced scale of improvement through these parameters within the selected urban spaces, physical interventions need be taken into consideration. Intelligibility of the immediate environment could be improved through extension or better connectivity to the highly integrated axial streets, which should consider a higher radius of observation in order to understand the overall axial network of the cities and towns. The least integrated streets within the axial network would require better signage and information system, as a short-term intervention, improving the legibility of the surrounding urban environment. With respect to the public transport accessibility levels, improved proximity to the nearest service station and increased service frequency would improve the overall access to the services. The connectivity indexes, though remained close to the desired values, could be further improved if cul-de-sacs were reduced within the urban network.

The pilot study identifies the perspectives with respect to pedestrian users as the focus group and looks forward to correlate the accessibility perspective through the bicycle users in future studies. The perspective of users with reduced mobility (e.g. wheelchair users) within these parameters would be inferred in further studies in order to gain a vision of how these spaces perform through the same parameters, which would lead to better understanding and reducing the barriers towards universal accessibility.

The pilot study findings assist in understanding the overall timeline during the collection of data and analysing the urban structure through diverse perspectives, which would be incorporated in future studies within selected urban spaces, based on similar land-use typologies in cities forming the Frankfurt Rhein-Main region. The diversity of spaces in different cities within an urban agglomeration and the prioritization of improvement in different mobility scales require a reflection in future research platforms.

\section{ACKNOWLEDGEMENTS}

This work has been [co-]funded by the LOEWE research funding program of the State of Hesse as part of the LOEWE research cluster „Infrastructure - Design - Society“/projectmo.de. 


\section{REFERENCES}

[1] Disability Inclusive and Accessible Urban Development Network (DIAUD), The Inclusion Imperative: Towards Disability-inclusive and Accessible Urban Development, available at https://www.cbm.org/Publications-252011.php, 2016.

[2] Hessian Ministry of Economic Affairs, Energy, Traffic and State Development, Hessen - Strategie Mobilität 2035, available at https://www.mobileshessen2020.de/strategie2035, Wiesbaden, 2018.

[3] Schafer, P. \& Gilbert, A., All Roads Lead through Frankfurt, What to do - the Traffic Planning Perspective. Living the Region - Rhein-Main, The Redesign of a Metropolitan Region, Germany, pp. 100-105, 2018.

[4] Engwicht, D., Reclaiming our cities and Towns: Better Living with Less Traffic, New Society Publishers: Philadelphia, pp. 167-168, 1993.

[5] Litman, T., Evaluating Accessibility for Transportation Planning: Measuring People's Ability to Reach desired Goods and Activities, Victoria Transport Policy Institute: Canada, pp. 3-9, 2016.

[6] Bertolini, L., Spatial development patterns and public transport: the application of an analytical model in the Netherlands. Planning Practice and Research, 14(2), pp. 199210, 1999.

[7] Cristopher, G. \& Geoff, S., Advancements in Public Transport Accessibility Assessments for Development Control -A proposed Methodology, Capita Symonds Ltd Transport Consultancy, pp. 2-8, 2008.

[8] Hillier, B., Space is the Machine: A configurational Theory of Architecture, London, pp. 93-103, 1996.

[9] Hillier, B., Penn, A., Hanson, J., Grajewski, T. \& Xu, J., Natural movement: or, configuration and attraction in urban pedestrian movement. Environment and Planning B: Planning and Design, 20, pp. 29-66, 1993.

[10] Knöll, M., Neuheuser, K., Cleff, T. \& Rudolph-Cleff, A., A tool to predict perceived urban stress in open public spaces. Environment and Planning B: Urban Analytics and City Science, 45(4), pp. 797-813, 2017.

[11] Ewing, R., Best Development Practices: Doing the Right Thing and Making Money at the Same Time, American Planning Association: Chicago, pp. 12-22, 1996.

[12] DepthmapX development team, depthmapX (Version 0.6.0) [Computer software], available at https://github.com/SpaceGroupUCL/depthmapX, 2017.

[13] Burton, E. \& Mitchell, L., Inclusive Urban Design - Streets for Life, Architectural Press, Oxford, 2016.

[14] Murphy, R., The Central Business District: A study in urban geography, New York, pp 3-11, 2017. 